\title{
The Impact of Drug Addiction Among the Students of Tertiary Level in Bangladesh
}

\author{
Faruq Ahammed $^{1} \quad$ Shakil Ahmed $^{2} \quad$ Faruq Ahammed $^{1 *}$ \\ 1.Department of Statistics, Jahangirnagar University, Savar, Dhaka-1342, Bangladesh \\ 2.Department of Business Administration, FBE, Daffodil International University, Dhaka, Bangladesh
}

\begin{abstract}
Drug use is becoming a major issue all over the world and people are taking drug without thinking its stern effects. The effects of drug abuse are felt on many levels: personal, friends, family and societal. The present study attempt to get an idea of drug addiction among the university students of Bangladesh. A total of 200 respondents were taken as a sample from different academic years. The results revealed that Phensedyl is the most popular drug and Yaba is the second most popular drug among the respondents. However, the results also show that the highest number of students are taking drug with friends $(70 \%)$ and only a few students are taking drug alone. Moreover, most of the addicted students are buying drug from an agent. In addition, most of the students also mentioned that the habit of taking drugs affect their mental, physical health as well as their academic performances. Efforts are made so that our students have recreational areas with a variety of recreation activities like games and sports that may fully occupy them during weekends and evenings. Consequently, the concerned authorities should be empowered and provided with equipment to detect and arrest drug abusers, and those concerned with the drug business in the university campus and nearby area.
\end{abstract}

Keywords: Drug addiction, University students, Bangladesh

DOI: $10.7176 / \mathrm{JEP} / 10-7-03$

Publication date:March $31^{\text {st }} 2019$

\section{Introduction}

Drug uses and abuses are serious problems in the world. At present, people are taking drug all over the world without thinking its stern effects. Drug use is becoming a major issue all over the world, following the introduction of heroin and related substances. Almost every day one can hardly miss news or information on drug abuse, drug trafficking, or people caught in some kind of drug business, both at national and international levels. Many people use the terms 'drug use' 'substance abuse' and 'drug abuse' interchangeably. However, the term 'drug' is mainly used to refer to 'medicine', while substance abuse may include chemicals other than drugs, i.e., gasoline, cleaning fluids, glue, and other chemicals (Hendrikz, 1986). There is a common misconception that drug abuse has to do primarily with illegal drugs such as cocaine, marijuana, and heroin; or with illicit use of prescriptions and medication. There are many types of drugs that may be abused. For example, chloroquine and aspirin are drugs which are commonly abused and they may be fatal. Chloroquine is at times used by girls for abortion. Some people are said to combine aspirin and alcohol for a stronger drink. Also, youths abuse substances such as gasoline, cleaning fluids, glue and other chemicals. Therefore not all abused chemicals are drugs (Possi, 1996). Drug abuse is defined as the use of a mood-altering drug to change the way one feels. Drugs may be abused by inhaling, sniffing, swallowing, or injecting into oneself. The drug may be legal or illegal, all the same it may be used for legitimate or medical reasons (Van Cleve, et al., 1978).

Young people abuse drugs due to complex social and peer groups influence, frustration, depression, curiosity, sub-cultural and psychological environment that induce the youths to take drugs. The effects of drug abuse are felt on many levels: personal, friends, family and societal. Drug addiction leads to the disintegration of family lies. The drug addicts in a threat to the family because of the hostile behavior of the drug abuser the family is at risk. Normal activities of the family disrupt due to antisocial activities of the abuser. The drug addict youth drops out from school/college or university education. The service holder loses his job because of irregularities. Social isolation and alienation are very common. A family of the drug addict became isolated from the community the drug abuser swallows the lion share of family income because of buying drugs (Shazzad, et al., 2013). Hasam and Mushahid (2017) explore the causes of drug addiction in the urban life of Sylhet City in Bangladesh and suggests that a man can become addicted to drugs by the influence of frustration and peer group not influenced by the parental drug addiction. Hossain and Mamun (2006) observed that the drug addicts are involved in various social offenses such as stealing, hijacking, pickpocketing etc. and also indulged in unethical and immoral activities for collecting money to procure drugs.

Zaman et al. (2013) was carried out a cross-sectional study among 120 students of National Ideal School in Dhaka city in Bangladesh and suggests that the secondary school students have poor knowledge about the effect of drug abuse. Azad et al., (2010) conducted a survey among the students of different public and private universities in Bangladesh and found that smoking is associated with overall poor health and a variety of short-term adverse health effects among the students and may also be a marker for underlying mental health problems, such as 
depression among adolescents. They also found that the causes like- peer pressures; attractive advertising, desire to look mature etc. encourage young people to smoke. Akhter (2012) found that approximately 17 percent of the female residential students of Dhaka University are substance abusers. She also observed that the substance abuse is significantly associated with disturbed family peace, lack of attention of the parents and a wide array of frustration regarding study and future. Sani (2010) conclude that the students mainly took drugs to have fun or just for the sake of curiosity through their treatment taking attitude was in very low stage. Some previous studies have shown that students of different educational institutions are going to be addicted. Thus, the present study attempt to get an idea of drug addiction in the undergraduate students of Bangladesh.

\section{Methodology}

The primary data of this research is collected from the university students who lived in Dhaka city. Snowball sampling method has been employed in order to collect the data. So, the researcher at first contact with the students who have drug addicted and later they introduced researcher with other addicted friends/students. A total of 200 respondents were taken as a sample. Here, researcher collects the data from the study area by survey and used a structured questionnaire. The questionnaire is formed mainly based on demographic characteristics as well as drug addiction. IBM SPSS 22 was used to analyze the collected data.

\section{Results and Discussion}

The following Table 1 represents the frequency distribution of father's occupation of the respondents. From the table, it is seen that 39 percent student's father occupation is business however44 percent respondent's father is in either government or private job. Moreover, one in every ten father of the selected students is doing farming. It is also observed that a minority father of the student's politician and most of the fathers doing business.

Table 1: Frequency distribution of father's occupation of the respondents

\begin{tabular}{|l|c|c|}
\hline Father's occupation & Frequency & Percent \\
\hline Banker & 10 & 5.0 \\
\hline Business & 78 & 39.0 \\
\hline Farmer & 20 & 10.0 \\
\hline Govt. employee & 46 & 23.0 \\
\hline Politician & 8 & 4.0 \\
\hline Teacher & 32 & 16.0 \\
\hline Others & 6 & 3.0 \\
\hline Total & 200 & 100.0 \\
\hline
\end{tabular}

The frequency distribution of the mother's occupation of the respondents is presented in Table 2. Majority mother of the students is are housewife (69\%) and 24 percent of the total respondents' mother are Teacher. Only $3 \%$ mother of the total respondents are service holder.

Table 2: Frequency distribution of mother's occupation of the respondents

\begin{tabular}{|l|c|c|}
\hline Mother's occupation & Frequency & Percent \\
\hline Housewife & 138 & 69.0 \\
\hline Teacher & 48 & 24.0 \\
\hline Service holder & 6 & 3.0 \\
\hline Others & 8 & 4.0 \\
\hline Total & 200 & 100.0 \\
\hline
\end{tabular}

The following figure depicts the histogram of monthly family income of the students considered in this study. The shape of the distribution of monthly family income looks like a normal distribution. The graph shows that most of the student's monthly family income lies between 30 to 40 thousand Taka. Only a few students have a family income of less than 10 thousand and more than 60 thousand Taka. 


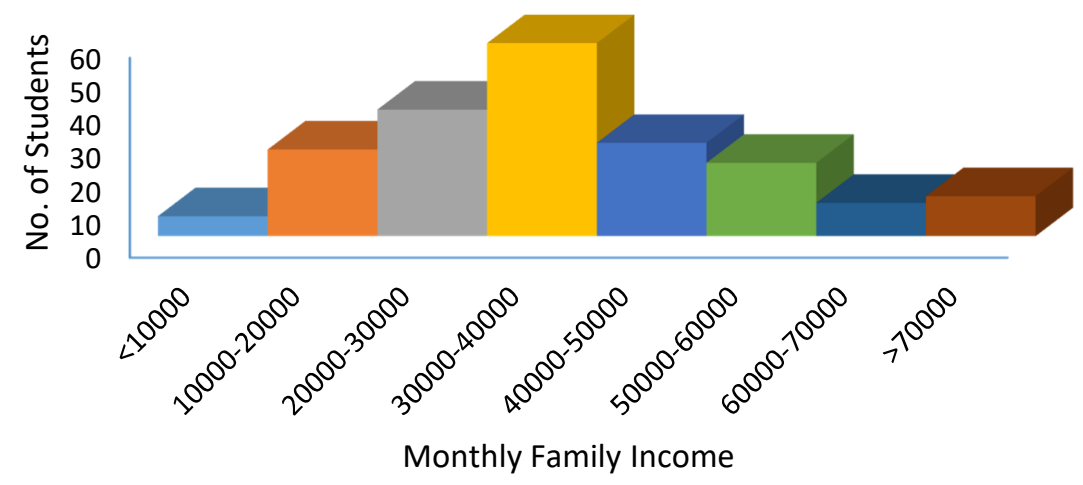

Figure 1: Histogram of the monthly family income.

Table 3 represents the frequency distribution of the different variables related to drug. From this table, it is seen that Phensedyl is the most popular drug and Yaba is the second most popular drug among the respondents. Only 15 percent of students take heroine while 19 percent of students take Ganja. It is observed that the selected students are taking drugs for one year and continue more than three years. Among the students, the highest percentage for the duration of taking drugs is two years (27\%), and $23 \%$ of the respondents are taking drug more than three years. The given Table 3 also shows that just under one-fifth of the respondents to be addicted in drug willingly whereas more than half of the respondents to be addicted in drug by their friends. The other reason includes bad results, failure in love and family condition. However, their percentages are low. It can be seen that the highest number of students are taking drug with friends (70\%) and only a few students are taking drug alone. Most of the addicted students are buying drug from an agent. From different nearby shops, they also collect drugs. It is also observed that about half of the students spend more than one thousand taka per month for buying drug.

Table 3: Frequency Distribution of the variables related to drug

\begin{tabular}{|c|c|c|c|c|c|}
\hline Drugs are taken & Frequency & Percent & Duration of taking drug & Frequency & Percent \\
\hline Phensedyl & 74 & 37.0 & One year & 50 & 25.0 \\
\hline Heroine & 30 & 15.0 & Two years & 54 & 27.0 \\
\hline Yaba & 68 & 29.0 & Three years & 50 & 25.0 \\
\hline Ganja & 38 & 19.0 & More than 3 years & 46 & 23.0 \\
\hline Total & 200 & 100.0 & Total & 200 & 100.0 \\
\hline $\begin{array}{l}\text { Reason for taking drug } \\
\text { firstly }\end{array}$ & Frequency & Percent & Companion during taking drug & Frequency & Percent \\
\hline Willingly & 32 & 16.0 & Friends & 140 & 70.0 \\
\hline Friends & 116 & 58.0 & Alone & 24 & 12.0 \\
\hline Bad result & 10 & 5.0 & Others & 36 & 18.0 \\
\hline Failure in love & 20 & 10.0 & $\begin{array}{c}\text { Total } \\
\end{array}$ & 200 & 100.0 \\
\hline Family condition & 22 & 11.0 & Cost of taking drug per month & Frequency & Percent \\
\hline Total & 200 & 100.0 & $<500$ & 28 & 14.0 \\
\hline Collection of drug & Frequency & Percent & $500-700$ & 20 & 10.0 \\
\hline Room delivery & 44 & 22.0 & $700-1000$ & 54 & 27.0 \\
\hline Nearest shop & 24 & 12.0 & $1000+$ & 98 & 49.0 \\
\hline Agent & 82 & 41.0 & $\begin{array}{c}\text { Total } \\
\end{array}$ & 200 & 100.0 \\
\hline Other way & 50 & 25.0 & $\begin{array}{c}\text { Impact on academic result of } \\
\text { taking drug }\end{array}$ & Frequency & Percent \\
\hline Total & 200 & 100.0 & Yes & 134 & 67.0 \\
\hline $\begin{array}{c}\text { Impact on health due to } \\
\text { taking drug }\end{array}$ & Frequency & Percent & No & 66 & 33.0 \\
\hline Yes & 162 & 81.0 & Total & 200 & 100.0 \\
\hline No & 38 & 19.0 & Wish for giving it up & Frequency & Percent \\
\hline Total & 200 & 100.0 & Yes & 136 & 68.0 \\
\hline Taken step to give up drug & Frequency & Percent & No & 64 & 32.0 \\
\hline Yes & 42 & 21.0 & Total & 200 & 100.0 \\
\hline No & 158 & 79.0 & & & \\
\hline Total & 200 & 100.0 & & & \\
\hline
\end{tabular}


From the Table 3 , it is seen that $81 \%$ of the respondents respond affirmatively that it is harmful in many ways whereas $19.0 \%$ of the respondents respond negatively that it is not harmful to their health. In addition, more than 60 percent of the respondents respond affirmatively that it affects their academic performances negatively whereas about one-third of the respondents respond negatively that it has no effect on their academic results. Moreover, approximately 70 percent of respondents want to give up it and about 30 percent of the respondents do not want to give it up i.e., they want to continue taking drugs. Finally, about one-fifth of students have taken different remedial steps to give it up and most of the respondents haven't taken any remedial step to give it up.

Table 4: Cross-tabulation of duration of taking drug and impact on health for taking drug

\begin{tabular}{|c|c|c|c|c|}
\hline \multirow{2}{*}{ Duration of taking drug } & \multicolumn{2}{|c|}{ Impact on health of taking drug } & \multirow{2}{*}{ Total } & \multirow{3}{*}{} \\
\cline { 2 - 3 } & Yes & No & \multirow{2}{*}{$\chi^{2}=7.458$} \\
One year & 42 & 8 & 50 & 54 \\
\hline Two years & 46 & 8 & 50 & \multirow{2}{*}{$\mathrm{p}$-value $=0.0262$} \\
\hline Three years & 34 & 16 & 46 & \\
\hline More than three years & 40 & 6 & 200 & \\
\hline Total & 162 & 38 & \\
\hline
\end{tabular}

Among the respondents, 21 percent of students are saying positively that there is a negative effect on health and 4 percent of students who are taking drug during one year are saying that there is no effect on health. Similarly, 23, 17 and 20 percent of students are saying positively that there is a negative effect on health for the students who are taking drugs for two, three and more than three years respectively. Now trying to test the hypothesis that there is an association between the duration of taking drugs and its impact on health. The p-value indicates that there is a significant association between these two variables at $5 \%$ level of significance.

Table 5: Cross-tabulation of duration of taking drug and its impact on academic results

\begin{tabular}{|c|c|c|c|c|}
\hline \multirow{2}{*}{ Duration of taking drug } & \multicolumn{2}{|c|}{ Impact on result of taking drug } & \multirow{2}{*}{ Total } & \multirow{7}{*}{$\begin{array}{c}\chi^{2}=8.294 \\
\text { p-value }=0.0181\end{array}$} \\
\hline & Yes & No & & \\
\hline One year & 26 & 24 & 50 & \\
\hline Two years & 36 & 18 & 54 & \\
\hline Three years & 36 & 14 & 50 & \\
\hline More than three years & 36 & 10 & 46 & \\
\hline Total & 134 & 66 & 200 & \\
\hline
\end{tabular}

From Table 5, it is observed that among the students considered in this study, $13 \%$ students are saying positively that there is a negative effect on their academic result whereas $12 \%$ students are saying that there is no effect on their academic performance. Similarly, more than half of the students who take drug during the period more than one year are saying positively that there is a negative effect of taking drugs on their academic result. However, the p-value of the chi-square statistic indicates that there is a strong association between the duration of taking drugs and academic performance at $5 \%$ level of significance.

\section{Conclusion}

Drug addiction beings on rapid erosion of educational and cultural, moral and family values. The addicts lose their professional and educational capabilities, self-dignity, and get involved in serious or petty criminal activities. Most of the addicted students taking several drugs like Phensedyl, Yaba, Heroine, Ganja etc. The shape of the monthly family income looks like a normal distribution i.e., it is almost symmetric. Figure 1, illustrates that the highest number of student's monthly family income lies between 30 and 40 thousand Taka. However, about 30 students have monthly income 10 to 20 thousand taka and has almost equal number of student's family income forty to fifty and fifty to sixty thousand taka whereas the second height income group is 20 to 30 thousand takas. Only a few students have a family income of less than 10 thousand and more than 60 thousand Taka (Taka is the currency of Bangladesh). Among the respondents, approximately one among five students are saying positively that there is a negative effect on health who are continuing to take drugs since one two, three and more than three years respectively. This paper also examines the relation between the duration of taking drugs and its impact on health. In order to test the hypothesis, the chi-square statistic is used here and its p-value indicates that there is a significant association between these two variables at 5\% level of significance which means that if a student takes drug long time has more health problems.

Students generally want to achieve a good score. Also, good score is positively related to getting a good job because in most of a good job employers mention the cutoff point on results. For example, an organization asks to apply those students who have GPA/CGPA more than 3.5 out of 4.0. So, results are important for every student. This paper also examines the relationship between the time duration of taking drug and their results. Here, the pvalue of the chi-square statistic designates that there is a strong association between the duration of taking drugs and academic performance at 5\% level of significance. However, most of the students also mentioned that the habit of taking drugs affect their mental, physical health as well as their academic performances. In addition, the 
important factor of taking drug is friend circle. Moreover, the majority of drug-addicted students want to give it up. So, the motivation will help them to avoid the abuse of drugs. Efforts are made so that our students have recreational areas with a variety of recreation activities like games and sports that may fully occupy them during weekends and evenings. It should be remembered that it is cheaper to prevent than cure disease. A disease may have detrimental effects even after curative measures have been taken. Consequently, the concerned authorities should be empowered and provided with equipment to detect and arrest drug abusers, and those concerned with the drug business in the university campus and nearby area to make a better environment of the campus.

\section{References}

Akter, J. (2012), "Prevalence of Substance Abuse among Female Residential Students of Dhaka University", ASA University Review 6(1), 115-127.

Azad, S. M. N., Hossain, M. M., \& Parveen, R. (2010), "Impacts of Smoking Habit by Young Generation in our Society", AIUB Journal of Business and Economics 10(1), 45-64.

Hasam, M. A. \& Mushahid, M. (2017), "Drug Addiction in Urban Life of Bangladesh: A Sociological Study for Exploring the Causes", Asia Pacific Journal of Multidisciplinary Research 5(2), 1-11.

Hendrikz, E. (1986), “Introduction to Education Psychology”, Hong Kong: Mcmillian Publishers.

Hossain, M. F., \& Mamun, M. (2006), "A Critical Analysis of Drug Addiction in Urban Life of Bangladesh", The Social Sciences 1(1), 60-64.

Possi, M. K. (1996), "Effects of Drug Abuse on Cognitive and Social Behaviours: A Potential Problem Among Youth In Tanzania", UTAFITI (New Series) 3(1), 111-128.

Shazzad, M. N., Abdal, S. J., Majumder, M. S. M., Sohel, J. U. A., Ali, S. M. M., \& Ahmed, S. (2013), "Drug Addiction in Bangladesh and its Effect", Medicine Today 25(2), 84-89.

Sani, M. N. (2010), "Drug addiction among undergraduate students of private universities in Bangladesh", Procedia Social and Behavioral Sciences 5, 498-501.

Van Cleve, S., Byrd, W., \& Revell, K. (1978), "Effects of drug use on cognitive and social behaviors", Waco, Texas: Word.

Zaman, M. S., Almajidi, W. A. \& Hurunnaher, (2013), "Knowledge on the Effects of Drug Abuse among the Students in A Selected High School in Dhaka City", Bangladesh Journal of Dental Research \& Education 3(2), 12-18. 